\title{
FUNDAMENTAL STUDY OF LOW-NOx COMBUSTION FLY ASH UTILIZATION
}

\author{
THIRD SEMI-ANNUAL REPORT
}

REPORTING PERIOD: OCTOBER 1, 1997 - APRIL 30, 1998
R.H. HURT AND E.M. SUUBERG (PRINCIPAL INVESTIGATORS) Y.M. GAO AND W.D. LILLY (STAFF)
I. KÜLAOTS (Ph.D. CANDIDATE) K. SMITH (UNDERGRADUATE ASSISTANT)

\author{
REPORT ISSUED: $\quad$ OCTOBER, 1998 \\ DOE AWARD NUMBER : DE-FG22-96PC96213-03 \\ ISSUING ORGANIZATION: DIVISION OF ENGINEERING \\ BROWN UNIVERSITY \\ PROVIDENCE, RI 02912 \\ REPORT PREPARED BY: T.M. SUUBERG \\ TEL. (401) 863-1420 \\ FAX (401) 863-1157
}

"US/DOE Patent Clearance is not required prior to the publication of this document" 


\section{United States Government Disclaimer}

This report was prepared as an account of work sponsored by an agency of the United States Government. Neither the United States Government nor any agency thereof, nor any of their employees, makes any warranty, express or implied, or assumes any legal responsibility for the accuracy, completeness, or usefulness of any information, apparatus, product, or process disclosed or represents that its use would not infringe privately owned rights. Reference herein to any specific commercial product, process, or service by trade name, trademark, manufacturer, or otherwise does not necessarily constitute or imply its endorsement, recommendation, or favoring by the United States Government or any agency thereof. The views and opinions of the authors expressed herein do not necessarily state or reflect those of the United States Government or any agency thereof. 


\begin{abstract}
This study is principally concerned with characterizing the organic part of coal combustion fly ashes. High carbon fly ashes are becoming more common as by-products of low-NOx combustion technology, and there is need to learn more about this fraction of the fly ash. The project team consists of two universities, Brown and Princeton, and an electrical utility, New England Power. A sample suite of over fifty fly ashes has been gathered from utilities across the United States, and includes ashes from a coals ranging in rank from bituminous to lignite. The characterizations of these ashes include standard tests (LOI, Foam Index), as well as more detailed characterizations of their surface areas, porosity, extractability and adsorption behavior. The ultimate goal is, by better characterizing the material, to enable broadening the range of applications for coal fly ash re-use beyond the current main market as a pozzolanic agent for concretes. The potential for high carboncontent fly ashes to substitute for activated carbons is receiving particular attention. The work performed to date has already revealed how very different the surfaces of different ashes produced by the same utility can be, with respect to polarity of the residual carbon. This can help explain the large variations in acceptability of these ashes as concrete additives.
\end{abstract}




\section{Table of Contents}

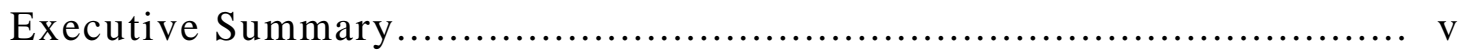

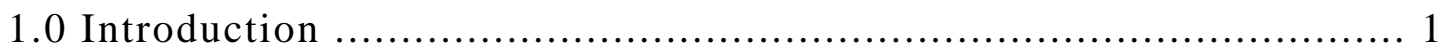

1.1 Project Description .............................................. 2

2.0 Progress During This Reporting Period...........................................5

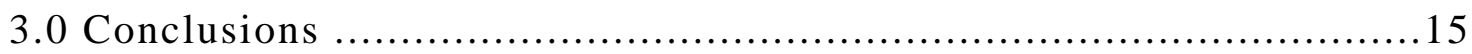

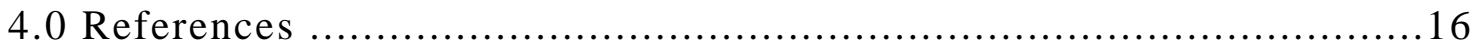




\title{
EXECUTIVE SUMMARY
}

\section{FUNDAMENTAL STUDY OF LOW-NOx COMBUSTION FLY ASH UTILIZATION (DE-FG22-96PC96213)}

\begin{abstract}
Background
The Nation faces a serious question concerning what to do with fly ash from coal-fired power stations. Only about $15 \%$ is presently utilized in cement and concrete products, which is by far the largest single market for this material. Since most of the remainder is landfilled, there is economic incentive for utilities to seek new opportunities for utilization. This project is concerned with better characterization of the fly ash, and identification of potential new uses of the ash. It is the "organic" portion of the ash, the unburned carbon, which may be the key to success in many new utilization schemes. The unburned carbon content has been significantly increased and altered by the introduction of new NOx control technology. The increased levels of carbon, and the different nature of the carbon, may offer new opportunities for ash re-utilization at the same time as these characteristics cause problems in concrete-based reuse.
\end{abstract}

\section{Project Overview}

This project involves a collaborative effort between two universities (Brown and Princeton) and an electric utility (New England Power). The goal is to provide a more basic understanding of the nature of the organic fractions of fly ash. Four specific tasks have been defined:

1. Characterization of the physical and chemical nature of ash organics. This task involves a) acquiring a suite of fly ash samples from utilities throughout the country, b) characterizing this set of samples, or a subset, with respect to organic (carbon and extractables) content, surface area and porosity. As part of this task, the oxidation reactivity of the unburned carbon is being measured.

2. Development of new screening tests to evaluate the samples with respect to various applications. This includes further development of a test for fine carbon content and identification of a simple alternative to the foam index test, both of which can serve as measures of suitability of the ash in concrete applications.

3. Characterization of the adsorption behavior of selected fly ashes relative to various organic and inorganic adsorbates.

4. Examination of the technical suitability of high-carbon coal fly ash as a low-cost alternative to activated carbon in adsorption applications.

\section{Progress to Date}

A suite of 56 samples, representative of utility practice across the country, has been assembled, and is being characterized as described in task 1 above. Tests of the adsorption behavior of the fly ashes have been performed, with an examination of the polar characteristics of their surfaces. This work has provided new insights into what determines whether a particular ash is suitable for concrete applications. The role of porosity in determining the adsorptive behavior of fly ashes has also been examined. The nature of the porosity of the carbons in fly ashes has received considerable attention during this reporting period. The oxidation reactivity of the residual carbon has also been examined for a broad range of samples. This reactivity does not seem to correlate well with the adsorption behavior of the carbon, but may provide insights into the nature of the carbons themselves. 


\subsection{INTRODUCTION}

The Nation's electric utilities produce an enormous amount of coal fly ash - recently about 48 million tons per year ${ }^{1}$. These utilities have long preferred recycling or reuse of the ash to landfill or pond disposal, but increasing landfill costs, liability concerns and other industry developments have shifted what was a mild preference for recycling to an imperative at many companies. At the present time, concrete products represent the major market for the ash, and consume about $1 / 6$ of the total produced ${ }^{1}$. Most of the remainder is presently landfilled. Many new market opportunities have been explored ${ }^{2}$, including lightweight aggregate, flowable fill, cement kiln feedstock, structural fill, alternate fuels, filtration media, ladle topping, fertilizer, casting sands and soil additives. To this list must be added sorbent applications, particularly for high carbon ashes from low- $\mathrm{NO}_{\mathrm{X}}$ combustion.

The widespread application of low- $\mathrm{NO}_{\mathrm{X}}$ combustion technologies has recently increased the carbon levels in fly ash at many utilities. In many instances, this has rendered the fly ash unsuitable for sale to the concrete industry ${ }^{3}$. Even in situations in which the carbon contents are within ASTM specifications, problems have still been reported with ashes from low- $\mathrm{NO}_{\mathrm{X}}$ combustion systems. Recent work at Brown University and New England Power has suggested that the problem might be related to changes in the form and sorptive properties of the carbon 4,5 . One of the goals of this project is development of a clearer understanding of what governs the performance of carbon-containing ash in concrete-type applications.

Unfortunately, most of the fundamental research on ash characterization has focused on the inorganic (majority) component of fly ash - its particle size, morphology, and chemical composition. It is the organic portion of the ash, consisting mainly of carbon, that could hold the key to success or failure in many new utilization schemes. It is the clearly significant role that carbon plays in concrete applications that has motivated the development of a variety of processes for carbon separation or removal from ash. These include processes based upon electrostatic separation, froth flotation, and carbon burnout outside the utility boiler. In the case of the 
separation schemes, streams considerably enriched in carbon (to tens of percent by mass) could become available. This may further expand the potential markets for application of the ash-derived materials to include some currently dominated by activated carbons, particularly powdered activated carbons.

In this project, Brown and Princeton Universities are teamed with New England Power to undertake a broad-based scientific investigation of the form, sorptive properties and behavior of the organic material in ash samples in order to help identify new commercial opportunities. The objectives of the research are to 1) thoroughly characterize the organic matter in ash with respect to form (including char-derived carbon, soot, and extractables), structure and surface properties, 2) examine the sorptive properties of ashes in technologically significant situations, and 3) to define new applications opportunities.

\subsection{PROJECT DESCRIPTION}

The project has been divided into four basic tasks, as described in the previous report. These tasks are being carried out by teams consisting of researchers from Brown, Princeton and New England Power. Project management is the responsibility of the team at Brown. Since the tasks have been described in some detail in the previous semi-annual report, only brief summaries are given here.

\section{Task 1- Physical and Chemical Characterization of Ash Organics. Sample acquisition}

This aspect is well under way, and will continue throughout the project. Interesting samples, characteristic of actual utility practice, are continually being solicited.

\section{Physical Characterization}

All samples are being characterized in-house at Brown with respect to organics content (LOI and extractable organics), carbon form and morphology, surface area, and porosity. As part 
of another program at Brown, this set of data is supplemented by the results of the "Foam Index" test, which is one of the key assays for suitability in concrete applications.

\section{Task 2- Analytical Technique Development}

Samples of fly ash must typically be tested for performance with respect to specific key additives in the concrete, the so-called Air Entraining Admixtures (AEAs). The AEAs are used to ensure that the final concrete will contain sufficient numbers of air bubbles, of the proper size, in order to impart good workability and freeze-thaw resistance to the concrete. The test used for this purpose is the "Foam Index" test, in which the required amount of AEA is measured in what is

essentially a titration test, the endpoint of which is determined by the stability of the foam created in a water solution of the AEA, which is a surfactant (see ref. 4-6). The recent work at Brown has strongly suggested that the unburned carbon is acting an adsorbent relative to the (organic) AEA surfactants. This work indicated that surface area of the unburned carbon in the fly ash is a key criterion in determining AEA requirements in the Foam Index test 4,5 . Another test examines the fine particle content of the $\mathrm{ash}^{4}$.

\section{Task 3- Adsorption Experiments Involving Strategic Compounds}

This work, being conducted at Brown, is investigating the sorptive behavior of ash organics (carbon), and the results will allow prediction of ash interactions with aqueous wastes, organic wastes, air toxic vapors, and air entraining admixtures in concrete. Testing will be performed in both water and air, to evaluate potential for purification applications in both media. An important characteristic of the ash carbons will be whether they have hydrophilic or hydrophobic surfaces. This will be determined both by measuring water vapor sorption isotherms, as well as by using new adsorption calorimetry methods 7 (see below). The adsorptive capacity of the surface for non-polar organic vapors will be determined by use of propane or butane, employing a recently described temperature programmed methodology 8 . Similarly, a model 
aromatic adsorbate, such as benzene or toluene, a basic adsorbate, such as ammonia or propyl amine, and a chlorinated hydrocarbon such as carbon tetrachloride, will be examined, with respect to vapor sorption capacity and kinetics. The suitability for water purification will be examined by experiments in which various components are partitioned onto the carbon from water. The experiments already under way with AEA compounds will provide some guidance as to selection of candidate ashes. The so-called "bottle point" method" can be used to examine the uptake of water contaminants such as p-nitrophenol or phenol, which can serve as reasonable (and widely used) benchmarks of performance.

\section{Task 4- Comparative evaluation against commercial activated carbons.}

In most of the applications considered for high-carbon ash, it competes directly with commercial activated carbons - materials that offer better performance but at a much higher cost. It is critical for the economic evaluations to have direct comparisons between the new materials (fly ash streams) and accepted commercial products. As a final task, we will therefore compile a summary of relevant information on commercial carbons, and to critically assess the performance of the fly ash streams against these competing materials.

\subsection{PROGRESS DURING THIS REPORTING PERIOD}

The project is well under way, and a number of results from the project have already been presented at conferences. Earlier presentations have been made at the 1997 International Conference on Coal Science ${ }^{10}$ and the 1997 International Fly Ash Utilization Symposium ${ }^{11}$. More recently, presentations have been made at the 1998 DOE-sponsored Conference on Unburned Carbon on Utility Fly $\mathrm{Ash}^{12}$ and are planned for a symposium on the Chemistry of Carbon in Coal Fly Ash organized by the PI's at the American Chemical Society's annual meeting ${ }^{13}$. In addition, another paper will be presented at the same conference by the Princeton-based members of the team $^{14}$. 
Earlier work has established a correlation between the adsorption of AEA and the surface area of carbons in the mixture ${ }^{4,5}$. Most fly ash carbon samples have surface areas much larger than would be expected from the external geometric area of the particles. This is because the carbon particles have a large amount of porosity including micropores $(<20 \AA)$, mesopores $(20 \AA-500 \AA)$

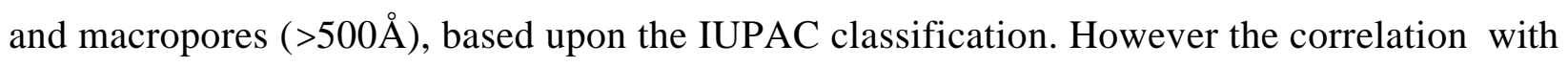
surface area was not perfect, which implied that there are other factors that also play a role in the AEA adsorption process. For example oxidative treatment of the ash (adding polar groups onto the carbon surface) can influence how effective the ash is in adsorbing AEA-s ${ }^{4}$.

The objective of this phase of the research program was to investigate the nature of the fly ash carbon, including both the nature of its porosity and polarity, and to see how these factors both influence the adsorption of AEA's. The discussion below is based mainly upon the adsorptive behavior of fly ash towards AEA's. This class of organic surfactants is certainly not representative of all aqueous solutes for which fly ash carbon might be a suitable sorbent, but it can be considered representative of a broad class of ionic surfactants.

\section{EXPERIMENTAL}

Samples

A sample bank containing 56 fly ash samples was assembled from commercial sources throughout the US. Samples were provided by both utilities and ash processors. Most of the samples were typical of ordinary operation, though a few were known to be of unusual character, having been deliberately prepared under "upset" conditions. Some of the samples were prepared by using electrostatic separation techniques (Separation Technology, Inc.) The fly ashes could be categorized using the usual ASTM classification system into three main types: class C, class F and petroleum coke co-fired fly ashes. 


\section{Loss-On-Ignition measurements}

Loss-on-ignition (LOI ) tests were performed on 1 gram samples, which were placed into small pre-weighed porcelain crucibles and then pre-dried in a laboratory oven at $130^{\circ} \mathrm{C}$ for two hours. After drying, samples were placed into a desiccator for cooling down to room temperature and then re-weighed. The samples were then placed into an air ventilated laboratory oven at $740^{\circ} \mathrm{C}$ for two hours, after which the samples were again cooled down in a desiccator and reweighed. This is basically the standard ASTM procedure, and it was verified that the two-hour combustion achieved constant weight. The change in weight between heating at $130^{\circ} \mathrm{C}$ and $740^{\circ} \mathrm{C}$ was the reported LOI, and is assumed to be the weight of unburned carbon in the original sample. Each fly ash sample was analyzed at least twice and an average percentage weight loss was calculated. The typical variance in the LOI values was quite small, and only in some cases did it get as high as $5 \%$ (relative basis), especially in ashes with LOI's lower than $0.5 \%$.

\section{Foam Index test}

The Foam Index test is a quick way to determine the suitability of a particular fly ash as a concrete additive. In our work, we examined two commonly used AEAs: Darex II $^{\mathrm{TM}}$ from Grace Construction Products and Air $40^{\mathrm{TM}}$ from Boral Material Technologies, Inc. The Foam Index tests involved placing two grams of fly ash, 8 grams of Portland cement and $25 \mathrm{ml}$ of deionized water into a $70 \mathrm{ml}$ cylindrical jar with a $40 \mathrm{~mm} \cdot \mathrm{I} . \mathrm{D}$. and $80 \mathrm{~mm}$ length. The jar was capped and thoroughly shaken for one minute to completely wet the cement and ash. A 10 vol.-\% aqueous solution of AEA was then added one drop $(0.02 \mathrm{ml})$ at time from a pipette gun. After addition of each drop the jar was capped and shaken for approximately 15 seconds, after which the lid was removed and liquid surface was observed. Before the endpoint of the test, the foam on the liquid surface is unstable. The endpoint was taken to occur when foam remained on the surface at least 45 seconds. A blank value was measured using only Portland cement in water. Subtraction of the 
blank from the actual test results gave the reported Foam Index (FI) value for the fly ash (in ml). The two different AEAs gave results that were related by a simple multiplicative factor, and results will therefore be given only for a single AEA (the Darex-II).

\section{Gas Adsorption}

In order to determine the surface area and porosity of fly ash samples, $\mathrm{N}_{2}$ gas adsorption experiments were performed using an Autosorb-1 system from Quantachrome Corp. The fly ash sample was placed into the appropriately sized sample holder and, prior to the analysis, was outgassed for several hours at constant temperature $(573 \mathrm{~K})$ in vacuum. Twenty adsorption and twenty desorption points were obtained, and from these sample porosity and surface area were determined. The Brunauer, Emmet and Teller (BET) theory ${ }^{15}$ was used for calculating surface areas. Dubinin-Radushkevitch (DR) theory ${ }^{15}$ was used for determining the microporosity of the fly ash samples. The main source of micropores in fly ashes is carbon. The inorganic part of the ash contains mostly macro- and mesopores.

\section{Flow Microcalorimetry}

Flow microcalorimetry experiments were performed using a Mark 3V Flow Microcalorimeter (FMC) manufactured by Microscal, Ltd. of London. These experiments involved measurement of the heats of adsorption of butanol on the (polar) surface of the sample. The sample cell $(0.20 \mathrm{ml})$ was filled with approximately $0.15 \mathrm{ml}$ of dry sample, which was washed into place with carrier fluid (heptane). Thermistors in the sample cell provide a temperature difference related to the heat release during adsorption. Measurements were made with the sample cell just above room temperature. Perfusor VI syringe pumps were used to maintain a constant $6.5 \mathrm{ml} /$ hour flow of carrier fluid in the system. The calorimeter baseline was established over several hours using the pure carrier fluid, heptane. The adsorbate, n-butanol, was dissolved in the heptane carrier and introduced from a second syringe. 
The method has been described in detail elsewhere ${ }^{16,17}$, and effectively involves titration of polar surface groups by butanol. Typically the saturation endpoint is observed by the time the butanol concentration in the heptane reaches about $1 \%$ by volume. The system was calibrated by feeding a known voltage, for a controlled time, to a precision resistor embedded in the sample cell. The polar surface area was determined using a published conversion factor, which for n-butanol on carbon is $6.7 \mathrm{~m}^{2} / \mathrm{J}$ of adsorption heat.

\section{RESULTS}

Our earlier work ${ }^{11}$ has shown that the primary adsorption sites for surfactants exist on the fly ash carbon. Generally, the higher the LOI (unburned carbon content) then the greater the surface available for AEA adsorption ${ }^{11}$. The deviations from the correlation of FI with surface area are due to factors not accounted for by surface area alone, e.g. the nature of the porosity or surface polarity.

\section{The role of surface area}

The main source of surface area in fly ash is its carbon. The surface area of the inorganic part of the ashes does not change much with the type of the fly ash and is $0.8 \mathrm{~m}^{2} / \mathrm{g} \pm 5 \%$ for all fly ashes examined. In Figure 1 the surface area per gram carbon is shown as a function of LOI for different ashes. Carbon surface area was calculated using the nitrogen adsorption isotherm and the BET equation. Subtracting the surface area of the inorganic part $\left(0.8 \mathrm{~m}^{2} / \mathrm{g}\right)$ from the total fly ash surface area and then dividing by LOI gives the carbon-based surface per gram carbon.

It can be seen that the typical class F fly ash has a carbon surface area in a range $30-70$

$\mathrm{m}^{2} / \mathrm{g}$-carbon. Some of the class $\mathrm{F}$ fly ashes shown have unusually high carbon surface areas. These fly ashes have generally been reported as unacceptable in concrete applications, either because they actually caused air entrainment difficulties, or because they were suspected of doing so. We could not verify these reports in all cases, and simply accepted the characterization of 
"bad" ashes that were provided by their suppliers. It should be kept in mind that an ash which is "bad" for concrete might actually be "good" for other sorbent applications, since it is likely to have a high sorption capacity for organics. The use of the term "bad" in Figure 1 and subsequent figures therefore represents, somewhat arbitrarily, the characterization of interest to the concrete producer.

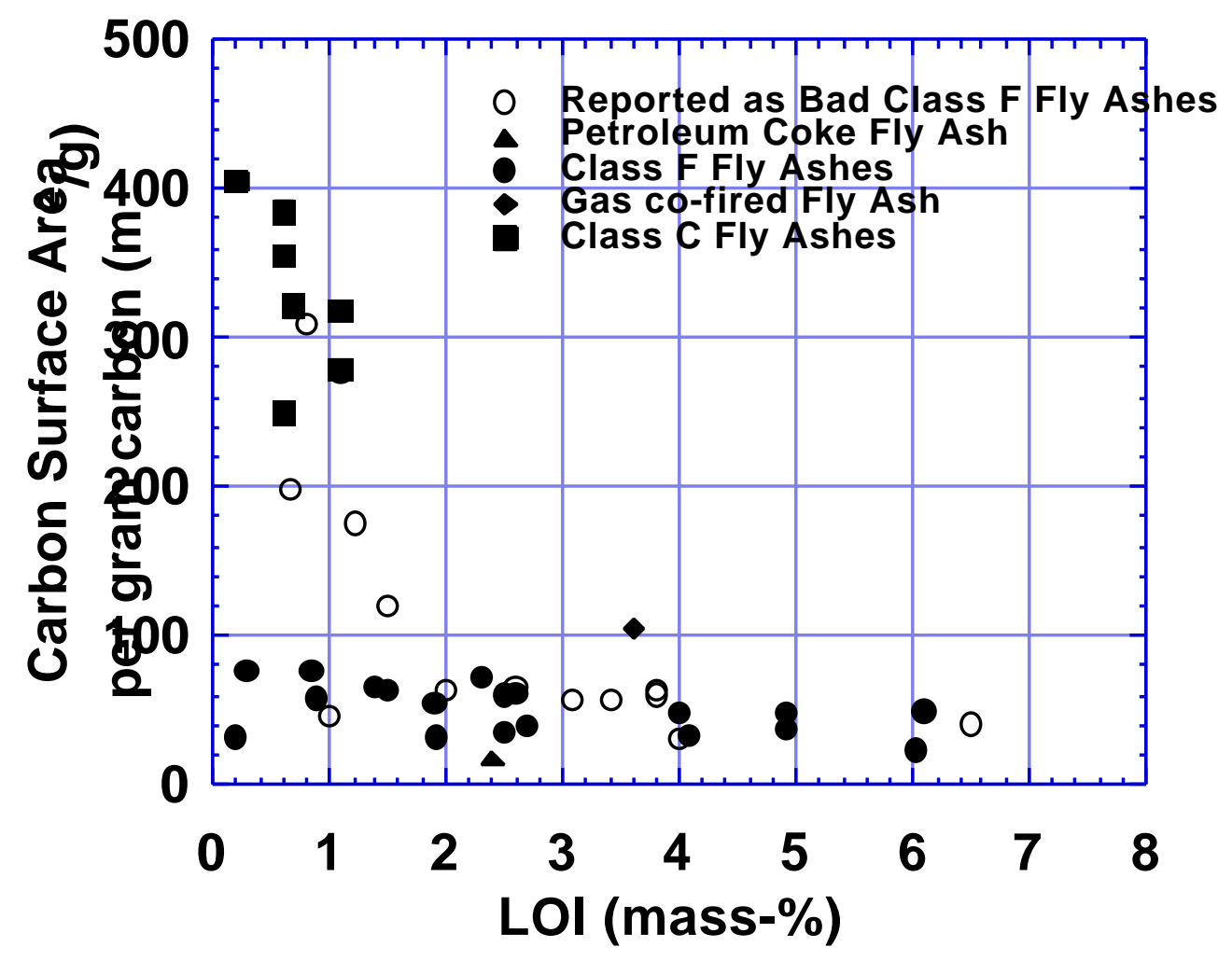

Figure 1. Surface area per gram carbon as a function of LOI for different types of fly ash.

Fly ashes from co-firing petroleum coke with coal have quite low carbon surface areas. This is because these ashes contain carbon which came mostly from the petroleum coke (96 mass $-\%)^{18}$. Petroleum coke is not very porous and thus its contribution to the surface area of the 
ash is small. These materials would be of little interest in sorbent applications, but could be of some interest in concrete applications, if their use is not ruled out on other grounds ( petroleum coke ashes are not necessarily exempt from RCRA regulations as are coal ashes).

As can be seen from Figure 1, all class C ashes in our sample bank have high carbon surface areas, in a range from $250-400 \mathrm{~m}^{2} / \mathrm{g}$. It is well known that low rank coals do not soften during pyrolysis as do the bituminous coals. Instead, they cross-link into a rigid char early during pyrolysis. Thus for low rank coals, which generally give class $\mathrm{C}$ fly ashes, the carbon is of high surface area, containing many micropores. In bituminous coals, as the coal starts to soften, porosity is largely lost, resulting in subsequently lower carbon surface areas. It should also be noted from Figure 1 that all the class $\mathrm{C}$ fly ashes also have low LOI values. With low LOI, accurate calculation of surface area per gram of carbon requires that caution be exercised because of the inherent uncertainty in LOI determination. However, it is unlikely that the uncertainty in LOI measurements would bring the surface area per gram carbon down to below $200 \mathrm{~m}^{2} / \mathrm{g}$. Thus class $\mathrm{C}$ fly ashes from our sample bank have higher areas per unit mass of carbon than do class $\mathrm{F}$ fly ashes. Their use as sorbent materials would be somewhat limited by the low LOI values in the ash. Large volumes of inorganic material would have to be tolerated in applications requiring significant carbon surface areas. 


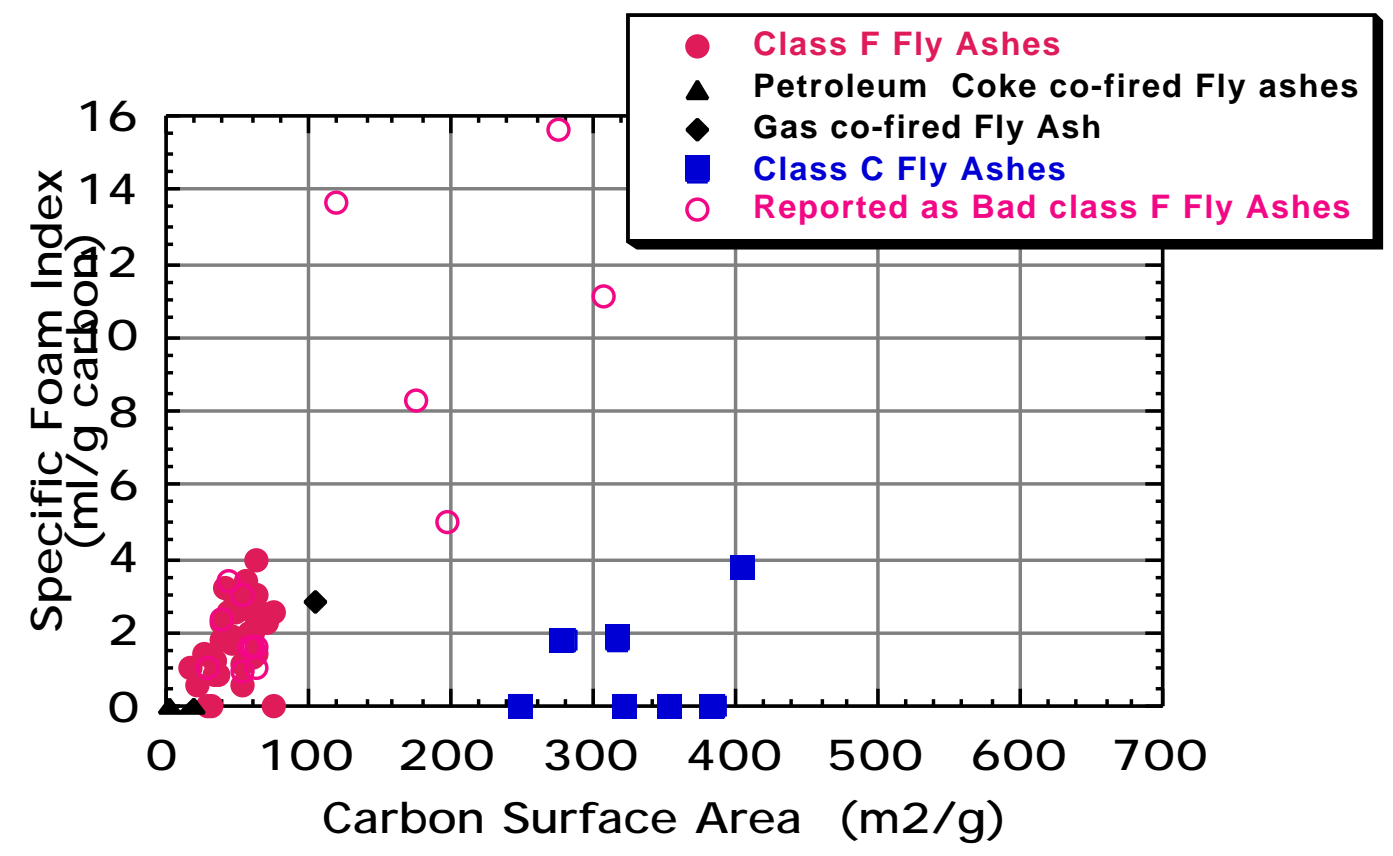

Figure 2. Specific foam index (10 vol.-\% Darex II solution) per gram carbon as a function of surface area per gram carbon, for different types of fly ash.

In Figure 2, specific foam index is given as a function of surface area. Specific foam index was calculated by dividing a fly ash foam index value, in $\mathrm{ml}$, by the LOI of the fly ash. Absolute values of the foam index are customarily examined to determine the quality of an ash for concrete. Here, the interest is in what carbon characteristics determine the foam index value and it is more instructive to examine a specific value, which is equivalent to a sorption capacity per unit mass of carbon in ash. The inorganic part of the fly ash does not contribute significantly to the value of foam index.

The results of Figure 2 show that the specific foam index of a sample varies widely, even at a particular value of surface area. None of the "good" (for concrete) class F fly ashes had high surface area however. Thus a high foam index value seems to require high surface area, but high 
surface areas do not assure high specific or absolute foam index, as the class $\mathrm{C}$ ashes demonstrate. Therefore neither LOI nor surface area alone can be used to predict acceptability of an ash for concrete applications. By extension, this also means that the utility of any ash in any adsorption application cannot be predicted from carbon content or surface area alone. Such a conclusion is not at all surprising, as it is well known in the activated carbon community. This further suggests that both the accessibility of the adsorptive surface and surface polarity may also play a role in determining the behavior of fly ashes, just as these factors play a role in determining the properties of an activated carbon.

\section{The role of polarity}

We have earlier shown that in addition to surface area, polarity is a factor that contributes to the variations in the amount of AEA uptake ${ }^{11}$. Polarity is determined by how many oxides (polar fractional groups) are available on the carbon surface. The inorganic part of fly ash is expected to be mostly polar, and this was verified experimentally. Thus the non-polar surface of an ash comes mostly from its non-oxidized carbon surface. Flow microcalorimetry, with n-butanol, can be used to determine this area ${ }^{16,17}$.

Polarity can be influenced by surface oxidation. We have earlier shown that the surfaces of oxidized carbons have a lower foam index than unoxidized ${ }^{4}$. In this study, a sample of class F ash (FA21, 6.1\% LOI) was deliberately oxidized. The specific foam index dropped from 2.49 to 0.66 . Further testing showed that the porosity was not affected by the oxidation, so these results confirm that polarity plays an important role in determining foam index.

Polarity alone cannot explain all of the differences in specific foam index observed in Figure 2. For example, the class $\mathrm{C}$ ash surfaces are not all $100 \%$ polar. Thus another factor must also play a role. We believe this factor to be the nature of the carbon porosity. 


\section{The role of porosity}

Nitrogen adsorption and desorption isotherms for fly ashes and their inorganic constituents were used in the determination of the mesopore content of the fly ash carbon. The choice was made to focus in mesopores, because it was clear that the failure to correlate specific foam index with specific surface implied that micropores alone could not explain observed trends. Dubinin-Radushkevitch theory was used to determine the microporosity of the fly ash carbon. Total pore volumes were calculated at a relative pressure of 0.995 . By subtracting the DR micropore volume from the calculated total pore volume and dividing that result by the LOI, the meso- plus macroporosity of the fly ash carbon (in ml/g-carbon) was determined. Due to the fact that most of this larger porosity is in mesopores, the term mesoporosity will be used for this volume. Selected fly ash samples have been picked for investigation of the influence of porosity on the specific foam index. 


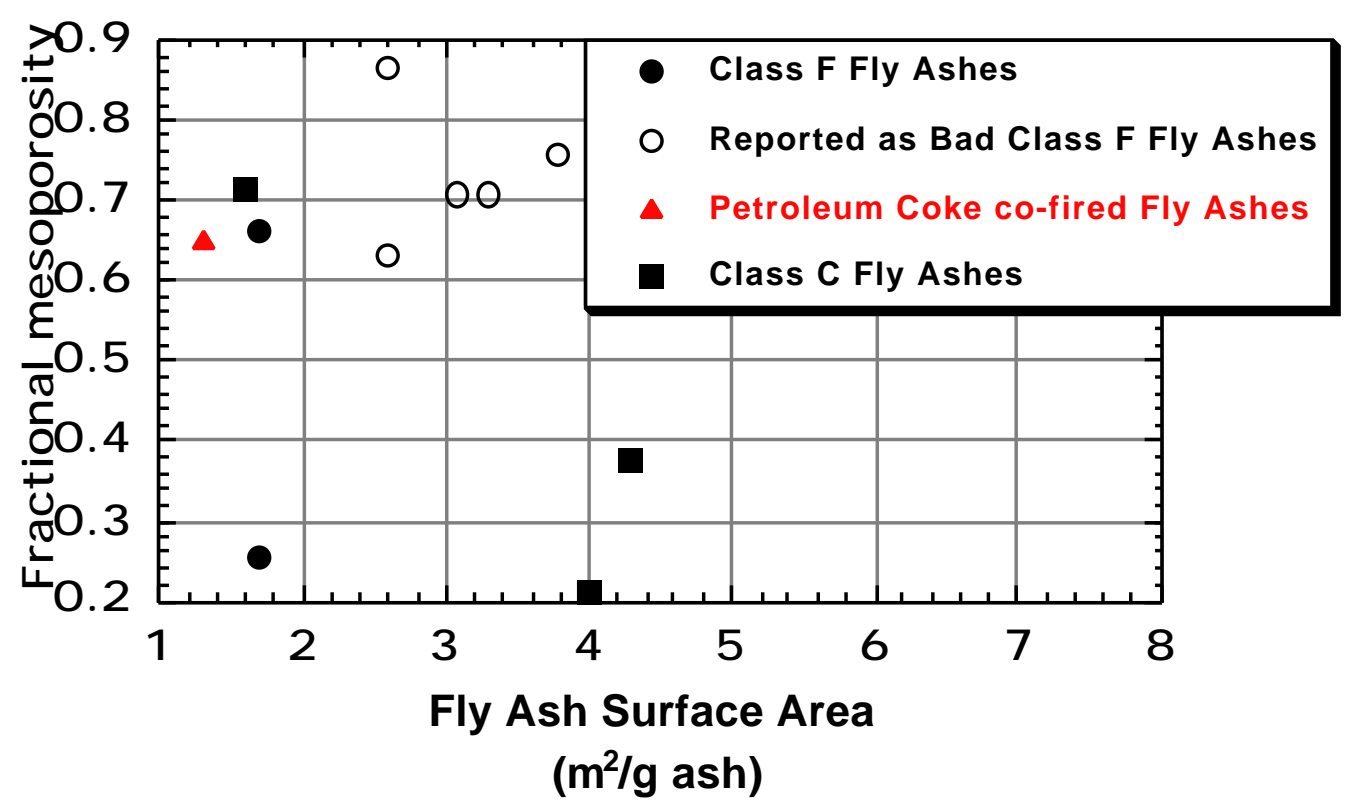

Figure 3 Fractional mesoporosity as a function of fly ash surface area.

Figure 3 shows the fractional mesoporosity, fly ash surface area and the quality of the ash. Poorly performing ashes (with respect to concrete applications) appear to have both a high fraction of their pore volume in mesoporosity and high surface area. This is believed to attributable to the fact that the so-called "bad" ashes have their high surface areas made available by a network of feeder mesopores. Class $\mathrm{C}$ fly ashes have comparatively high surface area, but low fractional mesoporosity. Thus most of the surface area for class $\mathrm{C}$ fly ashes is in micropores, and these may not be accessible to the large molecular species that make up AEAs. Petroleum coke co-fired fly ash has high fractional mesoporosity, but low surface area and thus also cannot adsorb much AEA.

It is well-known that in design of activated carbons for water purification applications, both the surface area (for capacity) and mesoporosity (for accessibility) need to be considered. 


\subsection{CONCLUSIONS}

During this period, attention has been turned to characterization of the carbon in fly ash as a porous adsorbent. This work confirmed that the adsorption capacity of a fly ash sample for AEA depends upon its carbon content. Generally speaking the higher the LOI of the sample, the higher the expected absolute foam index. Available surface area is an important factor in adsorption. Nitrogen and carbon dioxide isotherms have been used to confirm that the carbons are highly microporous. The surface area contained in micropores is presumably responsible for the AEA adsorption which renders certain fly ashes unsuitable for use in concretes, but this area may be useful in other adsorption applications. Not all fly ash carbons contain such microporous surface

area; fly ashes containing unburned petroleum coke contain little such area, and cannot adsorb any significant amounts of AEA.

Other factors being constant, a sample with higher surface area per unit mass of carbon generally gives higher adsorption of AEA. Class F fly ashes carbon have surface areas between $30-70 \mathrm{~m}^{2} / \mathrm{g}$-carbon. Some of the class F fly ashes, reported to be problem ashes in concrete applications, have higher surface areas. Higher surface areas were also reported for class C fly ashes, with areas typically in the range $250-400 \mathrm{~m}^{2} / \mathrm{g}$-carbon. However these materials had low absolute and specific foam indices. Thus factors beyond surface area must play a role in determining ash quality.

The nature of the carbon in fly ash explains why class $\mathrm{C}$ ashes having high surface areas do not have high adsorption capacities for AEA. In this case, accessibility of porosity is believed to explain the behavior. Class $\mathrm{C}$ fly ashes in our sample bank have carbon surface area mostly in micropores, and have few large feeder pores into the micropores. Thus large AEA molecules cannot reach the micropores. 
The polarity of the carbon surface can also explain some differences in adsorption activities for different fly ash samples. The more oxidized the fly ash carbon, the more polar its surface, and the lower its AEA adsorption capacity, since AEAs prefer to adsorb on nonpolar surfaces.

Combustion modifications can potentially influence both carbon polarity and porosity, as well as total carbon content. Thus in any particular case, there are several potential reasons for changes in suitability of the fly ash for concrete utilization or other sorption applications.

\subsection{REFERENCES}

1. Tyson, S. and Blackstock, T., Proc. Unburned Carbonaceous Material on Utility Fly Ash Conference, page 30, U.S. Dept. of Energy, April, 1995.

2. Fitzgerald, H., Chumley, J. and Waldrop, R., Proc. Unburned Carbonaceous Material on Utility Fly Ash Conference, p. 2, U.S. Dept. of Energy, April, 1995.

3. Hemmings, R.T., Venta, G.J., Golden, D.M., Proc. Unburned Carbonaceous Material on Utility Fly Ash Conference, p. 15, U.S. Dept. of Energy, April, 1995.

4. Gao, Y.-M., Shim, H.-S., Hurt, R.H., Suuberg, E.M. and Yang, N.Y.C., Energy and Fuels, 11, 457, 1997.

5. Freeman, E., Gao, Y.-M., Hurt, R.H., and Suuberg, E.M., Fuel, in press.

6. Helmuth, R. Fly Ash in Cement and Concrete, Portland Cement Association, 1987.

7. Groszek, A., Carbon, 25, 717 (1987).

8. Greenbank, M., Matviya, T., Tramposch, W., Proc. 21st Conf. Carbon, p. 369, Am. Carbon Society, 1993.

9. Randtke, S., Snoeyink, V., J. Am. Water Works Assoc., 75, 408 (1983).

10. Sabanegh, N., Gao, Y.-M., Suuberg, E.M., Hurt, R.H., "Interaction of Coal Fly Ash with Concrete Surfactants - Diffusional Transport and Adsorption”, Proc. 1997 ICCS, p. 1907, DGMK, Essen, Germany, 1997. 
11. Smith, K.A., Külaots, I., Hurt, R.H., Suuberg, E.M., “The Chemical Nature of Unburned Carbon Surfaces in Fly Ash - Implications for Utilization in Concrete", Proc. 1997 Int. Ash Utilization Symp., p. 650, University of Kentucky, 1997.

12. Külaots, I., Gao, Y.M., Hurt, R.H. and Suuberg, E.M., "Surface Characteristics of Unburned Carbon on Fly Ash and Their Influence on Foam Index Testing”, Proc. 1998 Conf. on Unburned Carbon in Utility Fly Ash, p. 53, U.S. D.O.E., May, 1998.

13. Külaots, I., Gao, Y.M., Hurt, R.H. and Suuberg, E.M., “ The Role of Polar Surface and Mesoporosity in Adsorption of Organics by Coal Fly Ash", ACS Div. Fuel Chemistry Preprints, 43(4), 980, (1998).

14. Wornat, M.J., Guran, S., Cheng, H. and Marsh, N.D., "Compositional Analysis of Organic Extracts From Fly Ash Samples of Coal-Burning Utilities", ACS Div. Fuel Chemistry Preprints, 43(4), 990, (1998).

15. Gregg, S.J. and Sing, K.S.W., Adsorption, Surface Area and Porosity, Academic Press, 1982.

16. Groszek, A.J. "Graphitic and Polar Surface Sites in Carbonaceous Solids”, Carbon, 25, 717 (1987).

17. Groszek, A.J. "Characterization of Microporous Carbon by Flow Microcalorimetry”, Carbon, , 27, 33 (1989).

18. Yu, J.H. Characterization of Fly Ash Derived from Petroleum Coke Co-Firing, ScB Thesis, Division of Engineering, Brown University, 1998 